\title{
Refractive status and optical components of premature babies with or without retinopathy of prematurity at 7 years old
}

\author{
Yang Wang, Lian-Hong Pi, Ru-Lian Zhao, Xiao-Hui Zhu, Ning Ke \\ Department of Ophthalmology, Children's Hospital of Chongqing Medical University, Ministry of Education Key Laboratory of Child Development \\ and Disorders, National Clinical Research Center for Child Health and Disorders (Chongqing), China International Science and Technology \\ Cooperation Base of Child Development and Critical Disorders, Chongqing Key Laboratory of Pediatrics, Chongqing 400014, China \\ Contributions: (I) Conception and design: Y Wang, LH Pi, N Ke; (II) Administrative support: LH Pi; (III) Provision of study materials or patients: LH \\ Pi, N Ke; (IV) Collection and assembly of data: Y Wang, RL Zhao, XH Zhu; (V) Data analysis and interpretation: Y Wang; (VI) Manuscript writing: \\ All authors; (VII) Final approval of manuscript: All authors. \\ Correspondence to: Ning Ke. Department of Ophthalmology, Children's Hospital of Chongqing Medical University, Ministry of Education Key \\ Laboratory of Child Development and Disorders, National Clinical Research Center for Child Health and Disorders (Chongqing), China \\ International Science and Technology Cooperation Base of Child Development and Critical Disorders, Chongqing Key Laboratory of Pediatrics, \\ Chongqing 400014, China. Email: 376018620@qq.com.
}

Background: This study aimed to investigate the refractive status and optical components of premature babies with or without retinopathy of prematurity (ROP) at 7 years old and to explore the influence of prematurity and ROP on the refractive status and optical components.

Methods: From January 2009 to February 2011, premature babies receiving fundus photographic screening (FPS) were recruited and divided into non-ROP group and ROP group. Full-term babies matched in age were recruited as controls. Auto-refractometer was employed to detect the corneal refractive power, corneal radius (CR) of curvature and corneal astigmatism, A-scan ultrasonography was performed to detect the anterior chamber depth (ACD), lens thickness (LT), vitreous thickness (VITR) and ocular axial length (AL), and retinoscopy was done following cycloplegia with $1 \%$ cyclopentolate in these babies at 7 years old. These parameters were compared among groups, and the correlations of gestational age and birth weight with the refractive status and optical components were further evaluated.

Results: Of 126 subjects, a total of 252 eyes were evaluated in this study, including 50 eyes of 25 subjects in ROP group (pre-threshold stage 1-3), 110 eyes of 55 subjects in non-ROP group and 92 eyes of 46 subjects in control group. The incidence of myopia was the highest in ROP group (9/50, 18\%), followed by nonROP group $(11 / 110 ; 10 \%)$ and control group $(6 / 92 ; 6.52 \%)$. The incidence of hyperopia was the highest in control group (21/92; 22.83\%), followed by ROP group (8/50; 16\%) and non-ROP group (10/110; 9.09\%). The incidence of astigmatism was the highest in ROP group (18/50; 36\%), followed by non-ROP group $(25 / 110 ; 22.73 \%)$ and control group $(12 / 92 ; 13.04 \%)$. The corneal astigmatism $(-1.58,-1.11,-0.86$ DC, $\mathrm{P}<0.01)$ and the mean degree of astigmatism $(1.38,1.17,0.64 \mathrm{DC}, \mathrm{P}<0.05)$ in ROP group and non-ROP group were significantly higher than those in control group. The corneal refractive power in ROP group was more potent as compared to non-ROP group and control group (43.98, 43.16, $42.99 \mathrm{D}, \mathrm{P}<0.05)$; the corneal curvature in ROP group was significantly higher than that in non-ROP group and control group (7.87, 7.71, $7.67 \mathrm{~mm}, \mathrm{P}<0.05)$; the ocular $\mathrm{AL}$ in ROP group and non-ROP group was significantly shorter than that in control group $(2.41,22.47,22.78 \mathrm{~mm}, \mathrm{P}<0.05)$. The LT in ROP group and non-ROP group was markedly thicker than that in control group (4.48, 4.45, $4.37 \mathrm{~mm}, \mathrm{P}>0.05)$; the ACD in ROP group and non-ROP group was markedly deeper than in control group (3.16, 3.12, $3.21 \mathrm{~mm}, \mathrm{P}>0.05)$. The gestational age was negatively related to corneal astigmatism $(\mathrm{r}=-0.208, \mathrm{P}=0.013)$ and astigmatism $(\mathrm{r}=-0.226, \mathrm{P}=0.004)$, but positively associated with ocular $\mathrm{AL}(\mathrm{r}=0.252, \mathrm{P}=0.005)$. The birth weight was negatively associated with corneal astigmatism $(\mathrm{r}=-0.30, \mathrm{P}<0.001)$, astigmatism $(\mathrm{r}=-0.267, \mathrm{P}=0.001)$, corneal refractive power $(\mathrm{r}=-0.255$, $\mathrm{P}=0.001)$ and corneal curvature $(\mathrm{r}=0.242, \mathrm{P}=0.001)$, but positively to ocular $\mathrm{AL}(\mathrm{r}=0.243, \mathrm{P}=0.001)$ and 
spherical equivalent refraction (SER) ( $\mathrm{r}=0.151, \mathrm{P}=0.028)$.

Conclusions: (I) Premature babies with or without ROP are susceptible to myopia and astigmatism; (II) low birth weight, prematurity and ROP synergistically influence the development of refractive status and optical components, resulting in myopia and astigmatism; (III) premature babies with or without ROP have increased corneal curvature and LT, which are related to the higher incidence of myopia and astigmatism.

Keywords: Premature baby; low birth weight; retinopathy of prematurity (ROP); optical components; refractive status

Submitted Dec 11, 2019. Accepted for publication Feb 06, 2020.

doi: $10.21037 /$ tp.2020.03.01

View this article at: http://dx.doi.org/10.21037/tp.2020.03.01

\section{Introduction}

With the development of obstetrics and the improvement of neonatal intensive care, the survival rate of premature babies increases significantly, and the focus in the medicine on premature babies have shifted from survival rate to quality of life. The ocular structure is still immature at birth for premature babies, and the incidence of eye diseases increases [including retinopathy of prematurity (ROP), ametropia, amblyopia and strabismus] significantly in these babies with the increase in survival rate of premature babies $(1,2)$. A variety of clinical studies and animal studies on visual electrophysiology have shown that ischemia and hypoxia in case of ROP may cause abnormal development of blood vessels, resulting in disordered oxygen delivery to the retina. In addition, ROP usually occurs at the time of physiological rapid growth of outer segment of rod cells and increase in erythrosine. Thus, the presence of ROP may cause abnormalities in the retinal neurons and the neurotransmitter conduction of retina. Although the spontaneous attenuation of ROP or interventions (such as laser treatment, cryotherapy and surgery) may improve the vascular development of the retina, the retinal dysfunction of the affected eyes continues, and ROP babies have elevated risk for ametropia (especially myopia) $(3,4)$. In a majority of full-term babies, both eyes are in a hyperopia status, but they are in an emmetropia or myopia status for premature babies. Several studies have reported that the incidence of myopia in premature babies is negatively related to the birth weight and gestational age, but positively to the severity of ROP (5). However, the mechanism underlying the pathogenesis of myopia in premature babies with and without ROP is still unclear. Some reports indicate that the pathogenesis of myopia is related to the increased corneal astigmatism, shallower anterior chamber depth (ACD) and elevated refractive power of the lens in premature babies with and without ROP $(6,7)$. Studies about the refractive status and optical components in premature babies with and without ROP are increasing, but most of them focus on infancy, and information about the refractive status in post-infancy children is limited. Moreover, much attention has been paid to the treatment of ROP with cryotherapy and photocoagulation therapy, and long-term follow-up has been employed in studies on refractive status $(8,9)$, but little is known about the long-term refractive status and visual development in children with mild ROP.

In our previous study, the refractive status and optical components were investigated in premature babies with and without mild ROP at 3-6 years old as well as in full-term babies. Results indicated premature babies with and without ROP were susceptible to myopia and astigmatism. In this study, we further investigated the refractive status and optical components in premature babies with and without ROP at 7 years old, and explore the influence of ROP and prematurity on the refractive status and optical components in these children.

\section{Methods}

\section{General characteristics}

From January 2009 to February 2011, premature babies receiving fundus photographic screening (FPS) were recruited from the Children's Hospital of Chongqing Medical University, and full-term babies matched in age were also enrolled as controls. Premature babies were divided into ROP group and non-ROP group according to the findings from FPS. In ROP group, there were 50 eyes 
of 25 subjects with pre-threshold 1-3 ROP; in non-ROP group, there were 110 eyes of 55 subjects without ROP; in control group, there were 92 eyes of 46 healthy babies. At 7 years after recruitment, the corneal refractive power, corneal curvature, ACD, lens thickness (LT), vitreous thickness (VITR), and ocular axial length (AL) were detected; retinoscopy was performed following cycloplegia. At the same time, the gestational age and birth weight of these subjects were also recorded. On the basis of following exclusion criteria and inclusion criteria, 130 subjects were recruited, but 2 subjects had incomplete medical information and 2 were lost to follow-up, and finally 126 subjects were included for final analysis.

Inclusion criteria: (I) gestational age was $<37$ weeks and birth weight was $<2,500 \mathrm{~g}$ (10); (II) the parents or guardians agreed with examinations, babies cooperated with examinations and informed consent was obtained before study; (III) subjects had no diseases of central nervous system or circulatory system (such as cerebral palsy and congenital heart disease); (IV) the refractive media had no turbidity and allowed retinoscopy; (V) there were no organic eye diseases except for ROP; (VI) prophase ROP for stage 1 to 3 thresholds.

Exclusion criteria: (I) gestational age was $\geq 37$ weeks or birth weight was $\geq 2,500 \mathrm{~g}$; (II) there was any factor causing the turbidity of refractive media, the pupils failed to be enlarged or there were other factors resulting in refractive difficulty; (III) subjects had a family history of high myopia.

\section{Screening for ROP}

First examination was performed at 4-6 weeks after birth or at the corrected gestational age of 32 weeks. Premature babies with gestational weeks $<37$ weeks and birth weight $<2,500 \mathrm{~g}$ were screened for ROP. According to the International Criteria for Retinopathy of Prematurity [1984] (11), ROP was diagnosed and staged: stage 1, 2 ROP in zone II without plus disease; stage 1, 2 ROP in zone III. Examination was done once weekly. For subjects with prethreshold ROP, the ocular fundus was closely monitored, and the examination was done once every 2-3 days; laser treatment of patients with threshold ROP and pre-threshold type I ROP within $48 \mathrm{~h}$; subjects with threshold 4-5 ROP received surgical intervention. Subjects without ROP and with incomplete vascularization of peripheral retina were followed up once every 2 weeks until complete retinal vascularization was present. Definition of pre-threshold type I ROP and threshold ROP (12): (I) pre-threshold type I ROP: any stage lesions in zone I with plus disease or stage 3 lesions with or without plus disease, or 2 or 3 stage lesions in zone II with plus disease; (II) threshold ROP : stage 3 lesions in zone I and zone II with plus disease, with a range of up to 5 consecutive hours, or discontinuous accumulation of up to 8; (III) plus disease: vasodilation and detour of at least 2 quadrant retina in the rear.

\section{Ophthalmologic examination}

A comprehensive ophthalmologic examination was done at 7 years after recruitment: the corneal refractive power, corneal curvature, ACD, LT, VITR, and ocular AL were detected; retinoscopy was performed after cycloplegia.

(I) Autorefractor (RK-8100; Topcon, Tokyo, Japan) was employed for the detection of corneal refractive power, corneal curvature and corneal astigmatism, which was performed three times, followed by the calculation of means (13).

(II) ACD, LT, VITR and ocular AL were detected with A-scan ultrasonography (KANGH CAS-2000, China). Detection was done 8 times, followed by calculation of means.

(III) Cycloplegic retinoscopy: 1\% cyclopentolate was used for cycloplegia. One drop was administered three times with the interval of $10 \mathrm{~min}$. At $20 \mathrm{~min}$ after last administration of cyclopentolate, the degree of cycloplegia was determined according to the pupillary light reflex. When the pupillary light reflex was present, another administration of cyclopentolate was done, and the degree of cycloplegia was determined according to the pupillary light reflex and pupil size. Cycloplegia is defined as the pupil size larger than $6 \mathrm{~mm}$ and absence of pupillary light reflex (absence of pupillary light reflex was present, but pupil size was not larger than $6 \mathrm{~mm}$ in several children). Streak retinoscope (YZ24; Six Six Vision Corp., Suzhou, China) was used for retinoscopy (5).

\section{Data collection and processing}

Auto-refractometry, A-scan ultrasonography, drug administration, retinoscopy and statistical analysis were 
performed by different investigators, aiming to reduce the errors, and the same investigator was responsible for one operation. In addition, subjects included in this study, investigators and data analyst were blind to the study protocol. Refraction is expressed as spherical equivalent refraction (SER) (SER = spherical refraction $+1 / 2$ cylindrical refraction). Hyperopia was defined as SER $\geq+2.00 \mathrm{D}$; myopia was defined as SER $\leq-0.50 \mathrm{D}$; astigmatism was defined as absolute cylindrical degree $\geq 1.00$ DC. The distribution of refraction is expressed as mean fraction \pm standard error $(\mathrm{SD})$. Data of each eye were included for analysis.

\section{Statistical analysis}

All the data were categorically recorded, listed and subjected to statistical analysis with SPSS version 20.0. The incidences of hypopia, hyperopia and astigmatism were compared with Chi-square test or Fisher exact test when the $20 \%$ of theoretical frequency was $<5$. When significant difference was present after analysis of variance, paired comparisons were done thrice with $\alpha$ at 0.0167 .

The means of continuous variables were compared with analysis of variance among three groups, and a value of $\mathrm{P}<0.05$ was considered statistically significant. When significant difference was observed after analysis of variance, LSD $t$-test was employed for comparisons.

Pearson correlation coefficient was calculated to evaluate the correlations of birth weight and gestational age with refractive status and optical components. The test standard is $\mathrm{P}<0.05$.

\section{Results}

Of 126 subjects (56 males and 70 females), the mean age was $7.42 \pm 0.33$ years. The mean gestational age was $34.13 \pm 4.48$ weeks at birth, and the mean body weight was $2190.12 \pm 842.65$ g. In addition, 25 subjects were included in ROP group, there were 55 subjects in non-ROP group, and 42 subjects were included in control group. Of 25 subjects with ROP, 16 had stage 1 ROP, 3 had stage 2 ROP, 1 had stage 3 ROP, 5 had pre-threshold ROP and none had threshold ROP. Bilateral ROP was found in 23 babies and unilateral ROP in 2 babies (right eye in 1 and left eye in 1).

There was significant difference in the gender among three groups $\left(\chi^{2}=9.333, \mathrm{P}=0.009\right)$ (Table 1$)$. Of three groups, the gestational age was the smallest and the birth weight was the lowest in ROP group, followed by non-ROP group and control group, and marked differences were observed in the gestational age and birth weight among three groups $(\mathrm{F}=679.972, \mathrm{P}<0.001 ; \mathrm{F}=718.992, \mathrm{P}<0.001)$ (Table 1). Further paired analysis showed significant differences in gestational age and birth weight between any two groups $(\mathrm{P}<0.01)$ (Table 1): gestational age: $\mathrm{ROP}$ vs. non-ROP, $\mathrm{F}=32.073, \mathrm{P}<0.001$; ROP vs. control, $\mathrm{F}=711.492, \mathrm{P}<0.001$; non-ROP vs. control, $\mathrm{F}=581.874, \mathrm{P}<0.001$; birth weight: ROP $v s$. non-ROP, $\mathrm{F}=13.256, \mathrm{P}=0.009$; $\mathrm{ROP} v s$. control, $\mathrm{F}=895.274, \mathrm{P}<0.001$; non-ROP vs. control, $\mathrm{F}=712.44$, $\mathrm{P}<0.001$.

\section{Incidence of ametropia}

The incidence of myopia was $18 \%(9 / 50)$ in ROP group, $10 \%(11 / 110)$ in non-ROP group and $6.52 \%(6 / 92)$ in control group, showing significant difference among groups $\left(\chi^{2}=6.814, \mathrm{P}<0.05\right)$. Further paired comparisons indicated no significant difference between ROP group and non-ROP group $(\mathrm{P}>0.05)$, but marked difference was observed between ROP group and control group $\left(\chi^{2}=8.243\right.$, $\mathrm{P}<0.05)$ and between non-ROP group and control group $\left(\chi^{2}=7.146, \mathrm{P}<0.05\right)$. The incidence of hyperopia was the highest in control group $(21 / 92 ; 22.83 \%)$, followed by ROP group $(8 / 50 ; 16 \%)$, and non-ROP group had the lowest incidence of hyperopia (10/110;9.09\%), and significant difference was observed among three groups $\left(\chi^{2}=7.24, \mathrm{P}<0.05\right)$. Further paired comparisons revealed marked difference between ROP group and control group $\left(\chi^{2}=10.245, \mathrm{P}<0.05\right)$ and between non-ROP group and control group $\left(\chi^{2}=7.275, \mathrm{P}<0.05\right)$, but there was no marked difference between ROP group and non-ROP group $\left(\chi^{2}=1.524, \mathrm{P}=0.467\right)$. The incidence of astigmatism in ROP group $(18 / 50 ; 36 \%)$ was higher than in non-ROP group $(25 / 110 ; 22.73 \%)$ and control group $(12 / 92 ; 13.04 \%)$, and significant difference was observed among three groups $\left(\chi^{2}=11.70, \mathrm{P}<0.01\right)$. Further paired comparisons indicated marked difference between ROP group and control group $\left(\chi^{2}=14.664, \mathrm{P}<0.05\right)$, but there was no significant difference between ROP group and non-ROP group $\left(\chi^{2}=3.081\right.$, $\mathrm{P}>0.05)$ and between non-ROP group and control group $\left(\chi^{2}=3.140, \mathrm{P}>0.05\right)$ (Figure 1).

\section{Refractive status and optical components}

In respect of refractive status, ROP group had the highest corneal astigmatism, followed by non-ROP group, control group had the lowest corneal astigmatism, and significant 
Table 1 Gender, gestational age and birth weight in three groups

\begin{tabular}{lccr}
\hline Information & ROP group & Non-ROP group & Control group \\
\hline Gender $(\mathrm{M} / \mathrm{F})^{\star}$ & $14 / 11^{\mathrm{a}}$ & $24 / 31^{\mathrm{a}, \mathrm{b}}$ & $18 / 28^{\mathrm{b}}$ \\
Gestational age $^{\star}$ & $29.28 \pm 2.40^{\mathrm{c}}$ & $31.94 \pm 1.96^{\mathrm{b}}$ & $39.39 \pm 0.93^{\mathrm{a}}$ \\
Birth weight* $^{*}$ & $1,452.24 \pm 65.96^{\mathrm{c}}$ & $1,690.91 \pm 33.28^{\mathrm{b}}$ & $3,309.43 \pm 52.96^{\mathrm{a}}$ \\
\hline
\end{tabular}

*, represents comments on statistical test data for tables only. There was significant difference between the three groups with different letters $\left({ }^{a, b}, q\right)$ in the same line $(\mathrm{P}<0.05$, one-way analysis of variance; least significant difference test). ROP, retinopathy of prematurity.

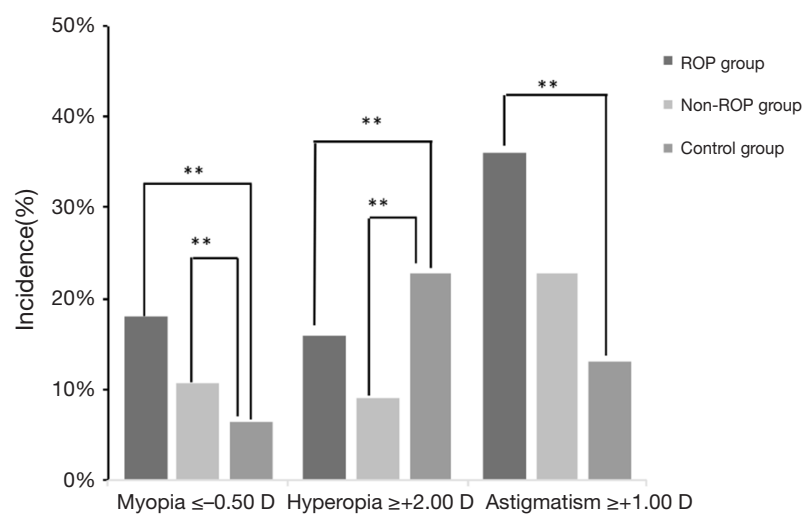

Figure 1 Different types of ametropia. X-axis: definitions for hyperopia, myopia and astigmatism. Incidences of hyperopia, myopia and astigmatism were determined in ROP group, nonROP group and control group. **, $\mathrm{P}<0.05$. ROP, retinopathy of prematurity.

difference was observed among groups $(\mathrm{F}=14.287, \mathrm{P}<0.01)$. Further paired comparisons indicated marked difference between any two groups $(\mathrm{P}<0.05)$. The astigmatism diopter was the highest in non-ROP group, followed by ROP group, controls had the lowest astigmatism diopter, and significant difference was observed among groups $(\mathrm{F}=6.287$, $\mathrm{P}<0.01)$. Further paired comparisons revealed marked difference between ROP group and control group and non-ROP group and control group $(\mathrm{P}<0.05)$. There was no significant difference in the SER among three groups $(\mathrm{F}=0.204, \mathrm{P}=0.808)$. In respect of optical components, marked differences were observed in the corneal refractive power $(\mathrm{F}=8.145, \mathrm{P}<0.05)$, corneal curvature $(\mathrm{F}=7.587$, $\mathrm{P}<0.05)$, and $\mathrm{AL}(\mathrm{F}=6.235, \mathrm{P}<0.05)$ among three groups. Further paired comparisons indicated significant differences in the corneal refractive power and corneal curvature between ROP group and non-ROP group and between ROP group and control group $(\mathrm{P}<0.05)$, but there were no marked differences between non-ROP group and control group $(\mathrm{P}>0.05)$. The $\mathrm{AL}$ was the longest in control group, followed by non-ROP group, and it was the shortest in ROP group. In addition, significant difference was observed between ROP group and control group and between nonROP group and control group $(\mathrm{P}<0.05)$, but there was no marked difference between ROP group and non-ROP group $(\mathrm{P}>0.05)$. The LT was the thickest in ROP group $(4.48 \mathrm{~mm})$, followed by non-ROP group $(4.45 \mathrm{~mm})$ and control group $(4.37 \mathrm{~mm})$. The ACD was the deepest in control group $(3.21 \mathrm{~mm})$, followed by ROP group $(3.16 \mathrm{~mm})$ and non-ROP group $(3.12 \mathrm{~mm})$. However, there were no marked differences in the LT $(\mathrm{F}=0.008, \mathrm{P}=0.986)$, ACD $(\mathrm{F}=0.734, \mathrm{P}=0.574)$ and VITR $(\mathrm{F}=2.343, \mathrm{P}=0.103)$ among three groups (Table 2).

\section{Correlations of gestational age and birth weight with refractive status and optical components}

Table 3 shows the correlations of gestational age and birth weight with refractive status and optical components. Gestational age was negatively related to corneal astigmatism $(\mathrm{r}=-0.204, \mathrm{P}=0.019)$ and astigmatism $(\mathrm{r}=-0.225, \mathrm{P}=0.006)$, but negatively to $\mathrm{AL}(\mathrm{r}=0.258$, $\mathrm{P}=0.005)$. Birth weight was negatively related to corneal astigmatism ( $\mathrm{r}=-0.278, \mathrm{P}=0.001)$, astigmatism $(\mathrm{r}=-0.282$, $\mathrm{P}<0.001)$, corneal refractive power $(\mathrm{r}=-0.252, \mathrm{P}=0.001)$, corneal curvature $(\mathrm{r}=-0.245, \mathrm{P}=0.001)$, but positively to $\mathrm{AL}(\mathrm{r}=0.248, \mathrm{P}=0.001)$ and SER $(\mathrm{r}=0.156, \mathrm{P}=0.039)$. However, the LT, VITR and ACD had no relationships with gestational age and birth weight in these children.

\section{Discussion}

The premature babies leave the uterus during the rapid maturation of version and thus the ocular structure is immature, which may result in ocular abnormalities such as myopia, astigmatism, hyperopia, amblyopia and strabismus. 
Table 2 Refractive status and optical components in three groups

\begin{tabular}{|c|c|c|c|}
\hline Refractive parameters & ROP group & Non-ROP group & Control group \\
\hline \multicolumn{4}{|l|}{ Refractive status } \\
\hline Corneal astigmatism (D)* & $-1.58 \pm 0.96^{a}$ & $-1.11 \pm 0.76^{b}$ & $-0.86 \pm 0.57^{c}$ \\
\hline Astigmatism (D)* & $1.38 \pm 0.87^{\mathrm{a}}$ & $1.77 \pm 0.982^{a}$ & $0.64 \pm 0.52^{b}$ \\
\hline SER (D) & $1.56 \pm 1.01$ & $1.40 \pm 0.64$ & $1.41 \pm 0.88$ \\
\hline \multicolumn{4}{|l|}{ Optical compositions } \\
\hline Corneal curvature $(\mathrm{mm})^{\star}$ & $7.87 \pm 0.36^{\mathrm{a}}$ & $7.71 \pm 0.32^{b}$ & $7.67 \pm 0.28^{b}$ \\
\hline $\mathrm{ACD}(\mathrm{mm})$ & $3.16 \pm 0.38$ & $3.12 \pm 0.26$ & $3.21 \pm 0.25$ \\
\hline $\mathrm{LT}(\mathrm{mm})$ & $4.48 \pm 0.29$ & $4.45 \pm 0.26$ & $4.37 \pm 0.26$ \\
\hline
\end{tabular}

${ }^{*}$, there was significant difference between the three groups with different letters $\left({ }^{a, b}, c\right)$ in the same line $(P<0.05$, one-way analysis of variance; least significant difference test). SER, spherical equivalent refraction; ACD, anterior chamber depth; LT, lens thickness; VITR, vitreous thickness; AL, axial length; ROP, retinopathy of prematurity.

Table 3 Correlations of gestational age and birth weight with refractive status and optical components

\begin{tabular}{|c|c|c|}
\hline Refractive parameters & Gestational age & Birth weight \\
\hline Corneal astigmatism (D) & $r=-0.204^{*}$ & $r=-0.278^{\star *}$ \\
\hline Astigmatism (D) & $r=-0.225^{\star \star}$ & $r=-0.282^{\star \star \star}$ \\
\hline SER (D) & $r=-0.042$ & $r=0.156^{\star}$ \\
\hline Mean corneal curvature (mm) & $r=0.065$ & $r=-0.245^{\star \star}$ \\
\hline \multicolumn{3}{|l|}{ Optical compositions } \\
\hline $\mathrm{ACD}(\mathrm{mm})$ & $r=0.015$ & $r=-0.019$ \\
\hline $\mathrm{LT}(\mathrm{mm})$ & $r=-0.028$ & $r=-0.089$ \\
\hline
\end{tabular}

${ }^{*}, \mathrm{P}<0.05 ;{ }^{* *}, \mathrm{P}<0.01 ;{ }^{\star * *}, \mathrm{P}<0.001$. SER, spherical equivalent refraction; $\mathrm{ACD}$, anterior chamber depth; LT, lens thickness; VITR, vitreous thickness; AL, axial length.

This risk is extremely high in the premature babies, and even moderate prematurity at gestational age of 32-36 weeks may also increase the risk for eye diseases (14-16). ROP is the most common eye disease in premature babies (17). The pre-threshold lesion usually diminishes, but recent studies indicate $(4,18)$ that even mild ROP or ROP in regressive stage is easy to affect the retinal development.
ROP may cause damage to rod cells in the retina, affecting the development of eyeball. There is evidence showing that the incidence of ametropia in children with ROP in regressive stage is higher than in healthy children (19), which is consistent with our previous finding.

In the present study, the incidence of hypopia was $18 \%$ in ROP children, $10 \%$ in non-ROP children and $6.25 \%$ 
in controls. The incidence of hypopia in ROP children of our study was similar to that reported by Robaei $e t a l$. $(15.0 \%)(20)$, but higher than that reported in children aged 3-6 years. This may be partially attributed to the natural increase in the incidence of hypopia over age. In addition, the learning intensity and close-range work are also important contributors. The incidence of astigmatism was $36 \%$ in ROP children, $22.73 \%$ in non-ROP children and $13.04 \%$ in controls, which were lower than that reported by Davitt et al. (42\%) (5). In the study of Davitt et al., the ROP was more severe and children with ROP received laser therapy; in our study, pre-threshold lesion or early stage ROP babies were included and they did not receive laser therapy or surgery. Of note, laser therapy and surgery may cause retinal scar formation, which might be related to the pathogenesis of astigmatism.

In our study, the incidences of hypopia and astigmatism in ROP group and non-ROP group were significantly higher than in control group. In addition, there was also marked difference in the incidence of hypopia between ROP group and control group as well as between non-ROP group and control group. This may suggest the influence of prematurity and ROP on the pathogenesis of hypopia. Significant difference in the incidence of astigmatism was observed between ROP group and control group, but there was no marked difference between non-ROP group and control group. This indicates ROP is a major contributor to the pathogenesis of astigmatism. Further analysis showed the cornea was steep, the anterior chamber was shallow, the lens was thick and the AL increased in ROP group and non-ROP group as compared to control group. These were consistent with previously reported $(6,7,21)$. Thus, we speculate that the changes in the optical components of anterior segment of the eye are closely related to the elevated incidences of hypopia and astigmatism in ROP group and non-ROP group. In normal eyes, the corneal refractive power is about $43.05 \mathrm{D}$, the refractive power of the lens is about $19 \mathrm{D}$, and both are the major optical components of the eyes. The determinants of ocular refractive power include corneal radius (CR), refractive power of the lens and axial ocular length, the abnormality in any one of them may cause hypopia, and the abnormal composition of them may also result in hypopia although they are normal (22). Fledelius et al. (23) investigated the refractive status of premature babies by follow up for 7-9 years, and they found the mean corneal curvature in premature babies with myopic refraction was larger than in full-term babies, regardless the history of ROP. In addition,
Cook et al. (16) found the close relationship between corneal curvature and myopic refraction in premature babies without ROP (mean gestational age: 29.4 weeks), and the incidence of hyperopia in these children was lower than in full-term babies. On the basis of above findings and our results, the increase in corneal curvature among different optical components may be one of major contributors to hypopia in premature babies.

Baker et al. (24) measured the axial ocular length, CR, LT and ACD and they found the LT increased, the axial ocular length reduced and CR elevated in subjects with a history of ROP as compared to hypopia subjects with same diopter and without a history of ROP. This indicates the changes in the corneal curvature and LT play a more important role in the ametropia as compared to axial ocular length in hypopia subjects with a history of ROP; in hypopia subjects without a history of ROP, the increase in axial ocular length is a major contributor to the ametropia. Chui et al. (25) alternatively administered 50\% oxygen and $10 \%$ oxygen to animals, and then MRI was employed for the measurement of biological parameters of the eyes. They found the ROP related hypopia was different from general hypopia, the corneal refraction accounted for $1 / 3$ of whole ocular refraction, the lens was the major contributor to the ocular refraction, and the axial ocular length reduced in case of ROP subjects. These were similar to the characteristics of optical components in ROP babies. Xie et al. (26) and Iwase et al. (13) found hypopia was closely related to the elevated LT and increased refractive power in ROP subjects, the LT increased with the increase in the severity of ROP, and premature babies (especially those with hypopia) had increased lens refraction as compared to full-term babies. Our results indicated the LT in ROP group was thicker than in non-ROP group and control group, which suggests the increased LT may be a major contributor to the elevated incidences of myopia and astigmatism in ROP babies.

The smaller the gestational age, the lower the birth weight is and the more immature the visual system is. Spencer et al. (27) conducted a study with long-term follow up and they found the risk for abnormal vision in premature babies with gestational age of $<28$ weeks was 4.1 times that in those with gestational age of $>28$ weeks. Crofts et al. (28) screened the visual status in 166 school age children and they found the risk for visual impairment in very low birth weight (birth weight $<1,500 \mathrm{~g}$ ) subjects was 26 times that in those with birth weight of 2,500-3,490 g. In our study, the mean birth weight was $1,452.24 \pm 65.96 \mathrm{~g}$ and mean gestational age was $29.28 \pm 2.40$ weeks in ROP 
babies; the mean birth weight was $1,690.91 \pm 33.28 \mathrm{~g}$ and mean gestational age was $31.94 \pm 1.96$ weeks. In addition, correlation analysis revealed the gestational age was negatively related to corneal astigmatism and astigmatism, and birth weight was also negatively associated with corneal astigmatism, astigmatism, corneal refractive power, and corneal curvature. This further confirms that small gestational age and low birth weight may increase the risk for hypopia and astigmatism.

Taken together, our study indicates the increases of hypopia and astigmatism increase in premature babies regardless the history of ROP, and the corneal curvature and LT increase, the anterior chamber becomes shallower, and the axial ocular length reduces in these babies. Moreover, low birth weight, prematurity and ROP may affect the optical components, and the changes in the corneal curvature and LT are the major contributors to the elevated increases of hypopia and astigmatism in premature babies. Thus, we recommend the early examination and follow-up of ocular function in premature babies regardless the history of ROP. Once ametropia is present, early intervention and treatment should be administered, aiming to improve the long-term vision and quality of life in these babies.

There were still limitations in this study. (I) The sample size was small, and further hierarchical analysis is needed on the basis of adjusted gestational age and birth weight in studies with large sample size; (II) visual electrophysiological examination and visual function examination will be administered in our future studies on ROP subjects, aiming to investigate the correlation of ROP with optic nerve development and optical components.

\section{Acknowledgments}

Funding: None.

\section{Footnote}

Conflicts of Interest: All authors have completed the ICMJE uniform disclosure form (available at http://dx.doi. org/10.21037/tp.2020.03.01). The authors have no conflicts of interest to declare.

Ethical Statement: The authors are accountable for all aspects of the work in ensuring that questions related to the accuracy or integrity of any part of the work are appropriately investigated and resolved.The study was approved by the Ethics Committee of the Children's
Hospital Affiliated to Chongqing Medical University [Lot No. (2019) Annual Review (Research) No. (216)].

Open Access Statement: This is an Open Access article distributed in accordance with the Creative Commons Attribution-NonCommercial-NoDerivs 4.0 International License (CC BY-NC-ND 4.0), which permits the noncommercial replication and distribution of the article with the strict proviso that no changes or edits are made and the original work is properly cited (including links to both the formal publication through the relevant DOI and the license). See: https://creativecommons.org/licenses/by-nc-nd/4.0/.

\section{References}

1. Yang CS, Wang AG, Shih YF, et al. Long-term biometric optic components of diode laser-treated threshold retinopathy of prematurity at 9 years of age. Acta Ophthalmol 2013;91:e276-82.

2. O'Connor AR, Stephenson TJ, Johnson A, et al. Change of refractive state and eye size in children of birth weight less than 1701 g. Br J Ophthalmol 2006;90:456-60.

3. Fulton $\mathrm{AB}$, Hansen RM, Moskowitz A. The cone electroretinogram in retinopathy of prematurity. Invest Ophthalmol Vis Sci 2008;49:814-9.

4. Fulton AB, Hansen RM, Moskowitz A, et al. The neurovascular retina in retinopathy of prematurity. Prog Retin Eye Res 2009;28:452-82.

5. Davitt BV, Quinn GE, Wallace DK, et al. Astigmatism progression in the early treatment for retinopathy of prematurity study to 6 years of age. Ophthalmology 2011;118:2326-9.

6. Al Oum M, Donati S, Cerri L, et al. Ocular alignment and refraction in preterm children at 1 and 6 years old. Clin Ophthalmol 2014;8:1263-8.

7. Ziylan Ş, Öztürk V, Yabaş-Kızıloğlu Ö, et al. Myopia, visual acuity and strabismus in the long term following treatment of retinopathy of prematurity. Turk J Pediatr 2014;56:518-23.

8. Choi MY, Park IK, Yu YS. Long term refractive outcome in eyes of preterm infants with and without retinopathy of prematurity: comparison of keratometric value, axial length, anterior chamber depth, and lens thickness. Br J Ophthalmol 2000;84:138-43.

9. Laws F, Laws D, Clark D. Cryotherapy and laser treatment for acute retinopathy of prematurity: refractive outcomes, a longitudinal study. Br J Ophthalmol 1997;81:12-5.

10. Varghese RM, Sreenivas V, Puliyel JM, et al. Refractive 
status at birth: its relation to newborn physical parameters at birth and gestational age. PLoS One 2009;4:e4469.

11. An international classification of retinopathy of prematurity. The Committee for the Classification of Retinopathy of Prematurity. Arch Ophthalmol 1984;102:1130-4.

12. Early Treatment for Retinopathy of Prematurity Cooperative Group. Revised indications for the treatment of retinopathy of prematurity: results of the early treatment for retinopathy of prematurity randomized trial. Arch Ophthalmol 2003;121:1684-94.

13. Iwase S, Kaneko H, Fujioka C, et al. A long-term followup of patients with retinopathy of prematurity treated with photocoagulation and cryotherapy. Nagoya J Med Sci 2014;76:121-8.

14. Hsieh CJ, Liu JW, Huang JS, et al. Refractive outcome of premature infants with or without retinopathy of prematurity at 2 years of age: a prospective controlled cohort study. Kaohsiung J Med Sci 2012;28:204-11.

15. Quinn GE, Dobson V, Davitt BV, et al. Progression of myopia and high myopia in the early treatment for retinopathy of prematurity study: findings to 3 years of age. Ophthalmology 2008;115:1058-64.e1.

16. Cook A, White S, Batterbury M, et al. Ocular growth and refractive error development in premature infants without retinopathy of prematurity. Invest Ophthalmol Vis Sci 2003;44:953-60.

17. Fielder AR, Reynolds JD. Retinopathy of prematurity: clinical aspects. Semin Neonatol 2001;6:461-75.

18. Mutlu FM, Küçükevcilioğlu M, Ceylan OM, et al. Risk factor analysis for long-term unfavorable ocular outcomes in children treated for retinopathy of prematurity. Turk J Pediatr 2013;55:35-41.

Cite this article as: Wang Y, Pi LH, Zhao RL, Zhu XH, Ke N. Refractive status and optical components of premature babies with or without retinopathy of prematurity at 7 years old. Transl Pediatr 2020;9(2):108-116. doi: 10.21037/tp.2020.03.01
19. Nelson LB. Myopia in retinopathy of prematurity. J Pediatr Ophthalmol Strabismus 2009;46:138.

20. Robaei D, Kifley A, Gole GA, et al. The impact of modest prematurity on visual function at age 6 years: findings from a population-based study. Arch Ophthalmol 2006;124:871-7.

21. Quinn GE, Dobson V, Davitt BV, et al. Progression of myopia and high myopia in the Early Treatment for Retinopathy of Prematurity study: findings at 4 to 6 years of age. J AAPOS 2013;17:124-8.

22. Chen J, Xie A, Hou L, et al. Cycloplegic and noncycloplegic refractions of Chinese neonatal infants. Invest Ophthalmol Vis Sci 2011;52:2456-61.

23. Fledelius HC. Myopia of prematurity, clinical patterns. A follow-up of Danish children now aged 3-9 years. Acta Ophthalmol Scand 1995;73:402-6.

24. Baker PS, Tasman W. Myopia in adults with retinopathy of prematurity. Am J Ophthalmol 2008;145:1090-4.

25. Chui TY, Bissig D, Berkowitz BA, et al. Refractive development in the "ROP Rat". J Ophthalmol 2012;2012:956705.

26. Xie Li, Wang Ping, Luo Yi, et al. Optical components of myopic children with a history of retinopathy of prematurity. Chinese Journal of Optometry Ophthalmology and Visual Science 2017;19:163-17.

27. Spencer R. Long-term visual outcomes in extremely low-birth-weight children (an American Ophthalmological Society thesis). Trans Am Ophthalmol Soc 2006; 104:493-516.

28. Crofts BJ, King R, Johnson A. The contribution of low birth weight to severe vision loss in a geographically defined population. Br J Ophthalmol 1998;82:9-13. 